\title{
A CASE OF FANCONI'S SYNDROME WITH A STUDY OF PEROXIDASE ACTIVITY OF THE ERYTHRON
}

\author{
BY \\ OTOTAKA HIGASHI, EIJI KOSEKI and MIZUE HIGUCHI \\ From the Department of Paediatrics, the Faculty of Medicine, Tohoku University, Sendai, Japan
}

(RECEIVED FOR PUBLICATION MAY 6, 1953)

Fanconi's syndrome, a constitutional hypoplastic anaemia associated with multiple congenital defects, is sufficiently uncommon to warrant reporting. This syndrome was first described by Fanconi in 1927. It has since been recognized in Germany (Genz, 1952), Greece (Cassimos and Zannos, 1952), Switzerland, Holland, France, Denmark, Great Britain and the United States, and has been reviewed by Reinhold, Neumark, Lightwood and Carter (1952). In the Japanese literature, the only case is that reported by Ida in 1952. We are reporting another instance of this syndrome in a Japanese girl, which, so far as we can determine, is the second to be published from Japan. In our case we have studied the alteration of the peroxidase activity of erythrons, and include our findings here.

\section{Case Report}

S.S., a 3-year-8-month-old Japanese girl, was admitted to the Tohoku University Hospital on September 19, 1952, for investigation of multiple congenital defects.

The parents were cousins and were healthy and had normal blood counts. The blood of both was $R h$ positive. Of six of their children. four seemed to be affected by a similar condition to the present case (Fig. 1).

The mother's pregnancy was uncomplicated. The patient was born at term after a normal delivery (weight was $2,600 \mathrm{~g}$.). At birth, malformations of the arms and

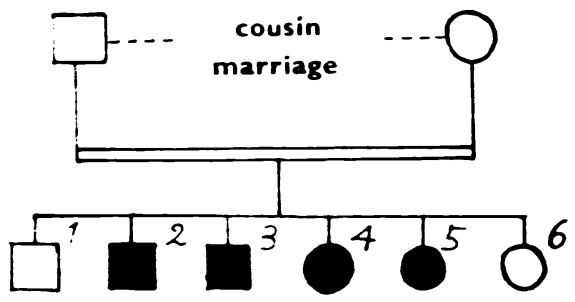

FIG. 1.-The pedigree of the present case.

1 and 6 are normal. 2 died at 5 years of age of profound anaemia with epistaxis. Multiple congenital defects similar to the present case were present. 3 and 4 showed multiple congenital defects of the skeletal system. These were foetuses examined after therapeutic abortion. 5 is the present case. fingers and an unusual facial appearance with a prominent left forehead, convergent squint and ptosis of the left upper eyelid were noticed. She was on a mixed diet. Her growth and development were slow. She sat alone at 15 months, walked alone at 18 months, and her gait was a waddle. She was always frail and was smaller than other children of the same age. She had had frequent colds.

She was a short, thin girl with pale, unpigmented mucous membranes and rather dark brown pigmentation of the face. She was $78 \mathrm{~cm}$. (normal $92 \mathrm{~cm}$.) tall, the head circumference was $45 \mathrm{~cm}$. (normal $48 \cdot 7 \mathrm{~cm}$.) and the chest circumference $43 \mathrm{~cm}$. (normal $50 \cdot 7 \mathrm{~cm}$.). Her weight was $8,250 \mathrm{~g}$. (normal $13,230 \mathrm{~g}$.). The facies was quite asymmetrical, because of the unusual prominence of the left forehead, a ptosis of the left upper eyelid and a paralytic convergent strabismus of the left eye (Fig. 2). The fundi appeared normal. The lungs and heart

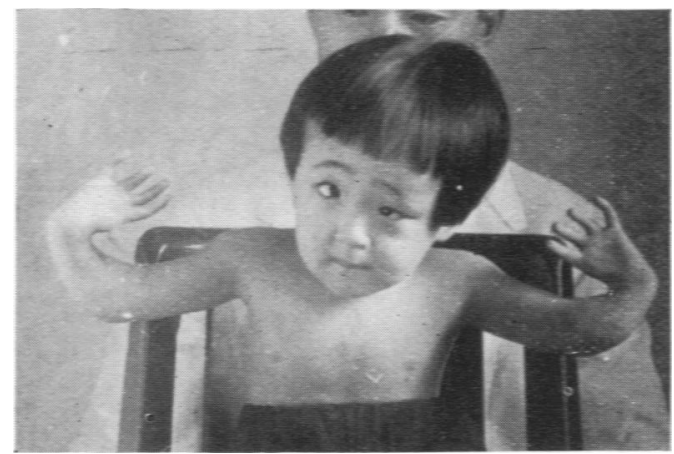

FIG. 2-Photograph of S.S.

were clear. The liver, spleen and lymph nodes were not palpated. The left arm was shorter than the right and curved to the radial side. The left thumb was absent and the right thumb was represented by a single bony rudiment hanging by a thread of skin from the right metacarpus. Both femoral heads were palpable. Deep tendon reflexes and abdominal reflexes were active. She had an intelligence quotient of $77^{\circ}$ on the revised Stanford-Binet scale.

Analysis of urine showed no abnormalities. An electroencephalogram and an electrocardiogram were 
normal. Radiographs of the sella turcica and the chest showed no marked abnormalities. A radiograph of the skeletal system disclosed the following abnormalities (Fig. 3): (1) The left thumb was absent and the right thumb was underdeveloped. (2) The wrist contained only two carpal centres of ossification (normally four centres are present). The left radius was absent. (4) Both hips were disclocated.

The chemical determinations of blood were nonprotein nitrogens $31 \mathrm{mg}$., sugar $115 \mathrm{mg}$., chloride $383 \mathrm{mg}$., phosphorus $4.3 \mathrm{mg}$., calcium $9.9 \mathrm{mg}$., total cholesterol $325 \mathrm{mg}$. (increased) and total protein $7 \cdot 1 \mathrm{~g}$. (albumin $3.33 \mathrm{~g}$., $x$-globulin $0.66 \mathrm{~g}$., $\beta$-globulin $1.11 \mathrm{~g}$., $\gamma$-globulin
$1.98 \mathrm{~g}$. (slight increase) per $100 \mathrm{ml}$.) Liver function tests were within normal limits, and were: thymol turbidity 4 Maclagan units, Takata-Ara reaction negative, bromsulphalein test 0 in half an hour, prothrombin time 15 seconds, icteric index 7 and delayed direct Van den Bergh reaction. A Thorn test showed that 222 eosinophils per c.mm. dropped to 201 eosinophils per c.mm. four hours after $0.2 \mathrm{ml}$. of adrenalin.

Haematological findings are shown in Tables 1 and 2.

The clinical course was uneventful except for one blood crisis. Upon admission, the child's blood picture showed slight anaemia, slight neutropenia and marked thrombocytopenia. However, soon after admission, her pallor

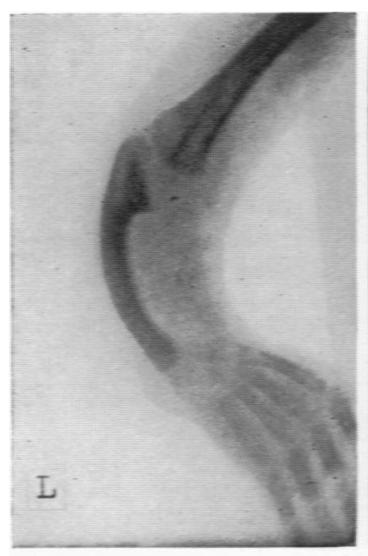

Fig. 3.-Radiographs of hands, arms and the hip.

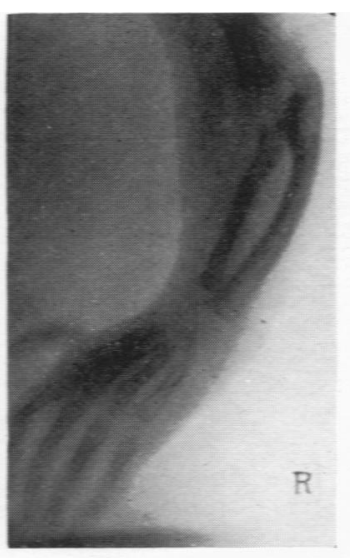

$3 \mathrm{~A}$

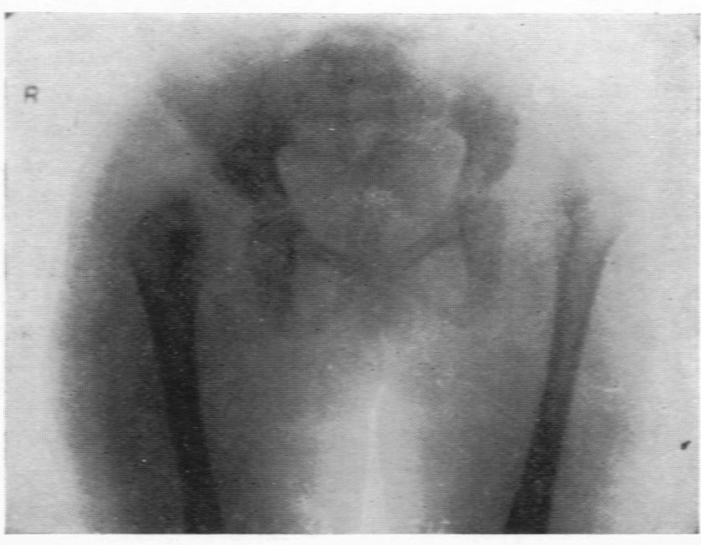

$3 \mathrm{~B}$

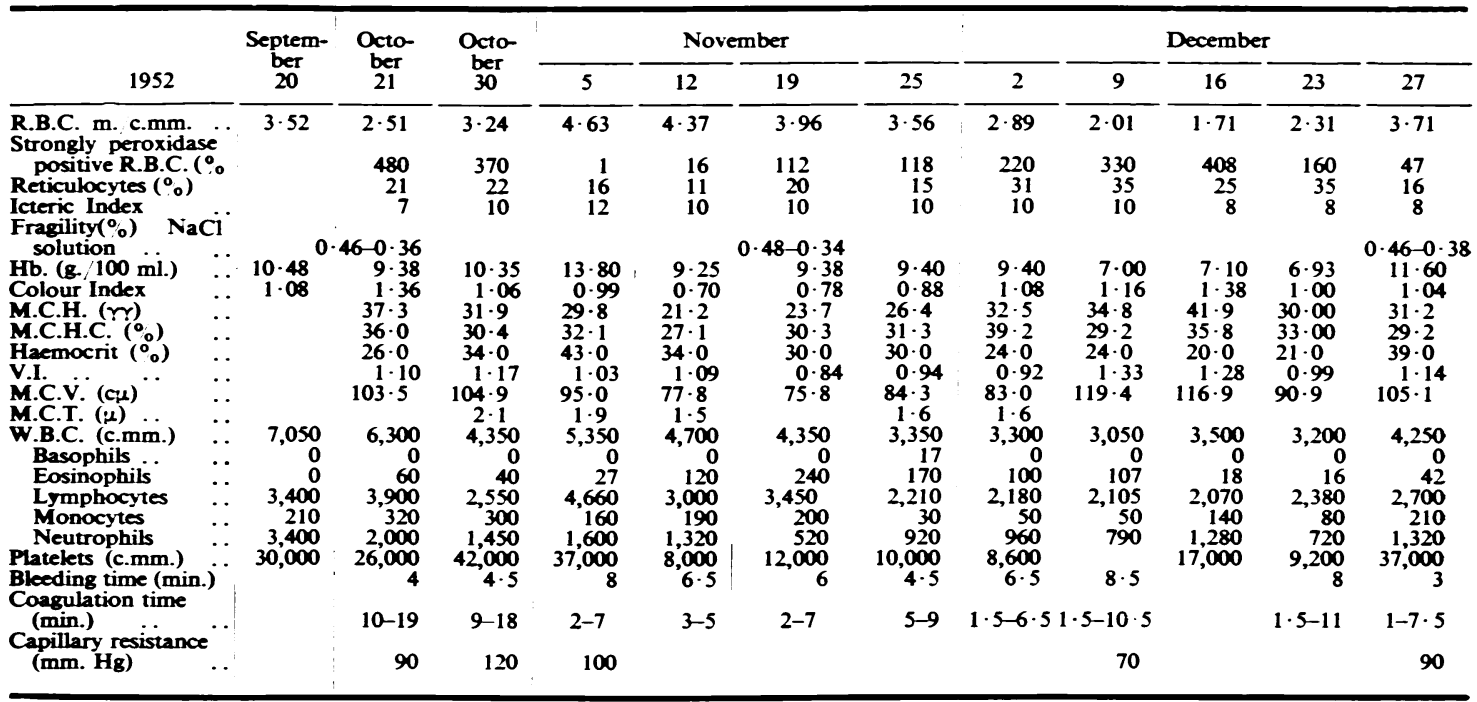

TABLE 1

THE haEMATOLOGICAL DATA OF THE PRESENT CASE 
TABLE 2

THE MYELOGRAM OF THE PRESENT CASE

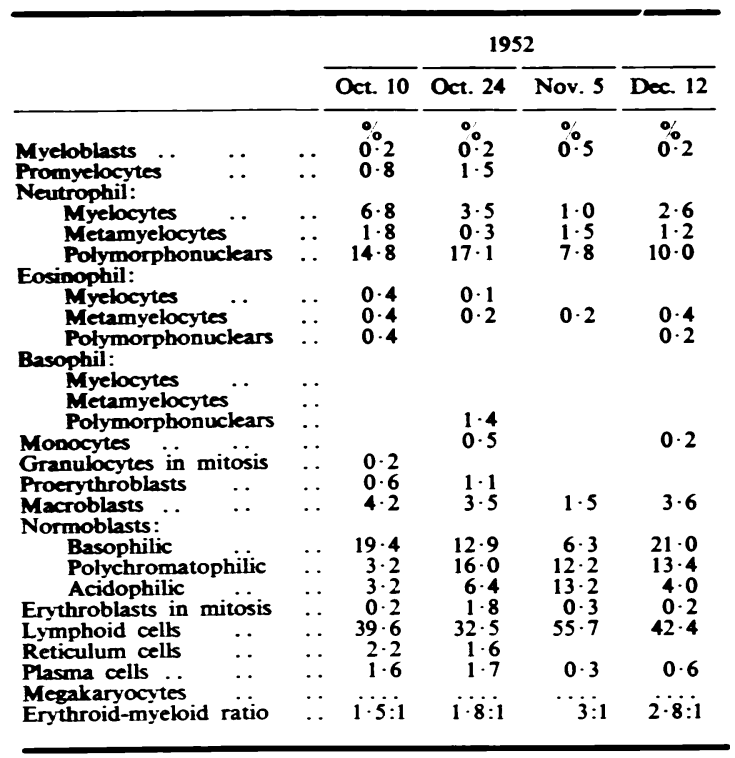

increased rapidly without any apparent cause, and a blood examination showed anaemia of the hyperchromic macrocytic type with marked anisocytosis, combined with moderate neutropenia with nuclear shift to the right and definite thrombocytopenia, i.e. pancytopenia. The red cell fragility and the icteric index were within normal limits. Urobilinogen was not found in the urine. The blood type was group $\mathrm{O} R \mathrm{R}$ positive. The sternal bone marrow picture showed a relative increase of erythroblasts and of lymphoid cells and a relative decrease of myeloid leucocytes. Virtually no megakaryocytes were seen.

She became gradually and progressively less alert and her appetite was reduced, but the blood transfusions (total 320 g.) raised the red cells and the haemoglobin to a normal level and increased her general activity. The

TABLE 3

PEROXIDASE PICTURE OF ERYTHROBLASTS IN THE STERNAL BONE MARROW

\begin{tabular}{|c|c|c|c|c|}
\hline \multicolumn{2}{|c|}{ The Peroxidase Activity } & \multirow{2}{*}{\multicolumn{3}{|c|}{ Percentage Pictures }} \\
\hline Cytoplasm & Nucleus & & & \\
\hline- & -- & 0 & 0 & $\mathbf{0}$ \\
\hline- & -- & 2 & 1 & $\mathbf{0}$ \\
\hline- & - & 5 & 4 & 2 \\
\hline- & - & 9 & 35 & 80 \\
\hline- & - & 27 & 50 & 15 \\
\hline$-\cdots$ & - & 53 & 10 & 3 \\
\hline--- & - & 4 & 0 & 0 \\
\hline \multicolumn{2}{|c|}{ Day of examination } & Oct. 24 & Nov. 5 & Dec. 12 \\
\hline
\end{tabular}

neutrophils, however, were not increased. A transient nuclear shift to the left in the neutrophils had occurred. The platelet count was not increased by the transfusions. Continuous treatment with iron, ferrum reductum $0.4 \mathrm{~g}$. daily, folic acid $15 \mathrm{mg}$. every three days, vitamin $B_{12} 15 y$ every three days, a liver preparation and other vitamins failed to maintain her red cell and haemoglobin levels and the same type of anaemia recurred. One month later, a whole blood transfusion, $400 \mathrm{ml}$. in all, was given with allegedly limited benefit and she was discharged in a fair state of general health.

\section{Comment}

The occurrence of a refractory anaemia and multiple congenital defects as presented in this case warrants the diagnosis of Fanconi's syndrome.

The pathogenesis of the refractory anaemia in this syndrome is obscure. In the absence of other aetiological agents, as Fanconi originally postulated, it is assumed to result from a inherent chromosomal defect. In this connexion, the following study of the peroxidase reaction of the erythron of this case may throw some light on the anaemia.

The peroxidase activity of the erythron was observed serially by the use of a new technique of the counting chamber copper peroxidase method for erythrocytes, which is a modification of Sato and Shoji's (1928) original method for leucocytes and was devised by one of the present authors (Higashi, 1953). The results showed that the peroxidase activity of erythrocytes seemed to vary inversely with the degree of anaemia. The strongly peroxidasepositive erythrocyte count was found to be highest when the peak of reticulocyte response developed after the first blood transfusion and this was thought to be an expression of the 'peroxidase response' (Higashi, 1952) of the erythron, suggesting that some parts of the bone marrow were still active in erythropoiesis.

On the other hand it was noticed that the nuclear peroxidase reaction of erythroblasts in the bone marrow was rather weak. The peroxidase picture in the marrow was determined three times and the results are given in Table 3. Erythroblasts in which the nucleus was strongly peroxidase-positive were rare, even when strongly peroxidase-positive erythrocytes were seen in great numbers in the peripheral blood. Such a picture was quite different from that found in a case of pernicious anaemia treated specifically. In the latter case, as reported in a previous paper, many erythroblasts with strongly peroxidase-positive nuclei occurred in the bone marrow at the early stage of blood regeneration. Consequently we raised the question whether some constitutional defect, which would manifest itself as a deficiency of the peroxidase, was present in the 
nucleus of erythroblasts of the present disease. We will be, however, unable to answer the question until sufficient data from peroxidase level determinations of erythrons in various kinds of anaemia become available.

\section{Summary}

A familial example of Fanconi's syndrome is reported. This is the second such case reported from Japan.

The peroxidase activity of the erythron was determined by a new technique of the counting chamber copper peroxidase method and the significance of alteration of the enzymic activity is discussed.

\section{REFERENCES}

Cassimos, C. and Zannos, L. (1952). Amer. J. Dis. Child., 84, 347.

Fanconi, G. (1927). Jb. Kinderheilk., 117, 257.

Genz, H. (1952). Arch. Kinderheilk., 145, 237.

Higashi, O. (1952). Tohoku J. exp. Med. 56, 330.

(1953). "A Counting Chamber Peroxidase Reaction Method for Erythrocytes.' Ibid. In the press.

Ida, N. (1952). Reported at the 55th Annual Meeting of the Japanese Pediatric Society in Sapporo City.

Reinhold, J. D. L., Neumark, E., Lightwood, R. and Carter, C. O. (1952). Blood, 7,915.

Sato, A. and Shoji, K. (1928). J. Lab. clin. Med., 13, 1058. 